\title{
GCU
}

Glasgow Caledonian

University

University for the Common Good

\section{The case for inclusive area profiling applied in geographic information systems}

Giupponi, Noemi; Thomson, Craig; Gibson, Lesley

Published in:

Proceedings of the ICE - Municipal Engineer

DOI:

10.1680/jmuen.17.00024

Publication date:

2018

Document Version

Author accepted manuscript

Link to publication in ResearchOnline

Citation for published version (Harvard):

Giupponi, N, Thomson, C \& Gibson, L 2018, 'The case for inclusive area profiling applied in geographic information systems', Proceedings of the ICE - Municipal Engineer, vol. 171, no. 3, pp. 173-182.

https://doi.org/10.1680/jmuen.17.00024

\section{General rights}

Copyright and moral rights for the publications made accessible in the public portal are retained by the authors and/or other copyright owners and it is a condition of accessing publications that users recognise and abide by the legal requirements associated with these rights.

Take down policy

If you believe that this document breaches copyright please view our takedown policy at https://edshare.gcu.ac.uk/id/eprint/5179 for details of how to contact us. 


\section{Introduction}

The re-emergence in contemporary planning of community representation and consultation

4 The principle of building cities reflecting human needs goes as far back as the rise of modern civilisations

5 with Ibn Khaldun understanding in $12^{\text {th }}$ Century Egypt that "the purpose of (building towns) is to have places for dwelling and shelter and (to ensure) that harmful things are kept away from the towns and that useful features are introduced and all the conveniences are made available to them” (Ibn Khaldun, 1969). A thousand years later, planning is still trying to keep 'harmful things' away and introducing 'useful features' such as better housing, efficient drainage systems, road networks and so on. The question arises, to what distinguishes contemporary planning from planning in $12^{\text {th }}$ century Egypt? Although planning still seems to deal with timeless tasks like the one of addressing the spatial problems associated with a growing or declining population, planning theory has evolved in such a way that it does not solely attempt to address the relationship between socio-economic development and the natural and built environment but, through a series of transformations which occurred in the $21^{\text {st }}$ century, it also attempts to help society articulate its own needs, especially the needs of the most disadvantaged and marginalised groups. As Hall (1988) narrates: "The change can be caricatured thus: in 1955, the typically newly graduated planner was at the drawing board, producing a diagram of desired land use; in 1965 s/he was analysing computer output of traffic patterns; in 1975 , s/he was talking late into the night with community groups in the attempt to organize against hostile forces in the world outside. ” (Hall, 1996:334)

In the 1960's, the idea of including people, their daily lives and routines in the design and development of cities, echoed with the failure of top-down large scale housing projects in the United States and Europe. As Marris (1998) explains: "for the sake of clearing slums or fostering economic development, governments regularly disrupted the ties of kinship, work and reciprocity which attached people to particular place”. As a reaction to this, Marris adds, "planning became associated with advocacy on behalf of those whose needs the welfare state did not meet and with the defence of communities, as places in which vital networks of relationship are embedded” (Marris, 1998) giving birth to a new generation of planners and a new theory of planning.

The contrast between the top-down and bottom up approaches to planning as practiced by the planners responsible for the slum clearance and the planners involved in advocacy planning, is the result of two different theoretical frameworks, and associated mind-sets, exemplified by Sandercock (1998) distinction between the conceptualisation of good planning as delivered by a 'heroic planner' and the conceptualisation of good planning as achieved by "working for social transformation in community based organizations". These two approaches have also been recently discussed in details by Rydin (2013) who instead focused more on the 'growth based' and 'community based' dimensions of planning. 
This paper wants to shed more light on how, within the context of contemporary planning, the skills, tools and knowledge of planners could be brought to bottom up planning and used to engage and empower citizens in "making their voices heard creating radical ways of doing, knowing and acting” (Sandercock, 1998).

\section{Community planning in the UK}

When US planning schools were elaborating theories for advocacy and radical planning, bottom-up planning practitioners in Europe were developing their own participatory approaches to urban design and development , spanning from Habraken's work on the role of participation in mass social housing schemes in the Netherlands (Habraken, 1972), to Community Technical Aid Centres (CTACs) helping tenants refurbishing and designing housing schemes in the UK (Jenkins, 2010).

Nevertheless, in the late 80's, CTACs and the broader community architecture movement started to decline as a result of a changing political and economic context in which a strong market orientated vision to urban development was being implemented to ensure economic growth in the British Cities struggling to fully recover from the blight of deindustrialisation (Spatial Agency, 2017). As recollected by Jenkins et al. (2010): “when Max Hutchinson took over from Rod Hackney as President of the RIBA in 1989, he promptly declared community architecture was dead: "It was not simply killed, it was overkilled. It was a PR exercise masquerading as a crusade"(cited in Towers, 1995: 217)”. Nonetheless, in 1995, Towers, a British planner notorious for his commitment to participatory planning explained that "Community architecture may be dormant but it is not dead.”, adding: "properly promoted, its revival (of community architecture) could do much to stimulate the development of alternative values; for the inner cities still characterised by social disintegration and physical decay, the revival of community architecture has never been more urgent".

In line with Towers' view, over the past decade, concerns have in fact re-emerged around the negative implications of failing to effectively include and consult communities in the design and planning of cities and this has resulted in the promotion of new concepts, practices as well as legal framework like the Community Empowerment (Scotland) Act 2015. A popular concept in the contemporary world of bottom up planning is the 'place-making' principle, a multi-faceted concept often associated to the critical work carried out in the 60's by Jane Jacobs, William Whyte and Kevin Lynch. In design and architecture we are increasing hearing the use of 'pop-up architecture' as a new mean to deliver social objectives by getting communities involved in temporary design projects creating public spaces with the aim of facilitating social interactions (The Guardian, 2013; Madanipor, 2017). Participatory and community oriented approaches to planning like place-making and pop-ups, however, are not exempt from critical appraisals with common criticisms that, when present, they could be tokenistic, 
1996; Friedmann, 2010; Monno V. \& Khakee A, 2012; Pollock\& Paddison 2014; Fincher et al. 2016; Schaller S. \& Guinand S., 2017).

Despite the criticisms, it has to be recognised that such practices have seen the value of community consultation and the inclusion of the marginalised being again publicised and, with the introduction of new legislation, policies and strategies (Scottish Parliament, 2014 ; Scottish Government 2015; Scottish Government 2016a; Local Government Association, 2017), they will represent, at least for the near future, some of the key issues that planning practitioners will have to deal with.

In the context of Scotland, for example, the idea of place making has filtered down to local planning policies (Glasgow City Council, 2017), with Charrettes, a collaborative design strategy originally developed in the 1960's, now being promoted by the Scottish Government to ensure communities are included in the shaping of our cities (Scottish Government, 2016b); another place making tool, the Place Standard Tool, has also been recently recognised for its contribution to better addressing people's needs and concerns about the places where they live (Scottish Government, 2017).

This paper will bring attention to a participatory tool/activity understood to enhance dialogues with communities during consultation processes: community mapping. In particular, it illustrates how community mapping carried out during consultation events could be integrated to Geographic Information Systems and subsequently used during traditional neighbourhood profiling (Scottish Government 2014; Scotland Census, 2017).

\section{Rationale and overall aim of research}

This research recognises that community consultation activities where communities and citizens are asked to either reflect their knowledge and understandings of the place or state preferences over different spatial scenarios, have (re)-gained importance in urban regeneration processes. Consultation facilitators and mediators employ a range of community participation tools and techniques which are seen to be evolving rapidly with the introduction of new technologies. From simple Q\&A sessions, brainstorming, sketching and paper mapping, to more sophisticated tools like Participatory Geographic Information System (PGIS), 3D modelling and digital or non-digital gaming techniques, the range of tools used during consultation processes vary by type and kind. It is acknowledged that guidelines already exists on how to carry out community consultation with a portfolio of methods (Scottish Executive, 2007) and that new technologies like ESRI Community maps and Story Maps are being increasing used for engaging with citizens. In addition to this, previous research on asset mapping for community development in the non-profit sector has also explored the challenges and principles of community mapping (Mathie \& Cunningham, 2003 ; Brundley et al. 2017). 
However, more research is required to identify the strengths and limitations of specific tools and techniques (Kheir, 1999; Brown \& Kytta, 2014).

4

This research is based on the assumption that community mapping should eventually inform decision making, improve sense making activities as well as problem framing, by reflecting the spatial representations of people's life worlds which are not accessible through traditional area profiling based on Census data (Scotland Census, 2017). Without discussing the extent to which this is achieved or not in the contemporary world of practice, this paper focuses on how this could be achieved and explores the role of design and modelling in facilitating the use of community mapping in decision making processes.

The utilisation of information technologies in top down and bottom up planning as well as the functionalist approaches of geodemography and GIS in neighbourhood targeting has been demonstrated in the work of Nedovic-Budic Z (2000), Deas (2003), Rydin (2007), Harris et al. (2005), Crampton (2006), Longley (2012) and many others. Although decision makers have access to a consistent set of indicators (like the Index of Multiple Deprivation) applied for comparative purposes when making funding decisions, criticisms have grown that these indicators lacked the ability to engage with subjective representations of spatial realities as perceived by individuals living, for example, within an area undergoing regeneration because they tend to focus on objective data such as unemployment, crime etc. As a consequence, this research investigates whether, within the current 'planning fashion' for bottom up planning, there may be a need for integrating, using design principles, subjective and objective representations of spatial realities by decreasing the distances between what Lefebvre described as the 'lived space' of communities and the 'abstract space' of planners and developers (Lefebvre, 1991).

\section{Research strategy and methods}

This research adopts a pragmatic approach to the study of planning support system as offered by Brömmelstroet (2016) and follows Kolb’s learning cycle (Kolb,1984) by a) combining theory and practice and b) expanding the traditional stages of research from 'observing and reflecting' and 'forming abstract concepts', to ‘testing in new situations' and gaining 'concrete experience'.

After having identified the problems with existing community mapping techniques using i) a literature review, ii) seven semi structured interviews to senior planners from five local authorities across the West of Scotland and iii) two observational studies, the paper based community map called Submap (Giupponi and Thomson 2016) was developed. Nineteen Gorbals residents were then asked, using different sampling methods, to use Submap to illustrate their life worlds in relation to their neighbourhood and a GIS relational database was ultimately developed to store the content of the maps. 
The testing of this mapping procedure (design, sampling, data entry, visualisation) was used to explore the potential and challenges of storing community mappings in GIS with the aim of relating them to existing objective area profiles extracted from Census statistics such as the IMD. It is finally argued that the integration 'by design' of spatial representations of subjective life worlds to traditional GIS, could aid inclusive area profiling by decreasing the distances between expertise and experience.

The following five different stages of research are illustrated in the next sections:

1) Literature review to establish the context in which area profiling of communities has evolved and the challenges it has encountered;

2) Interviews with seven senior urban planners across five different local authorities in West of Scotland to investigate existing practices and perspectives over the use of mapping and different datasets to represent communities;

3) Observational studies and engagement with community mapping groups;

4) Submap: The design and modelling of a new community mapping procedure

5) Establish Lessons for the future and conclusions

\section{Literature review}

\section{Planning Support Systems and area profiling}

Area profiling is a function of contemporary information technologies aiding spatial decision making in urban planning, known in the literature as Planning Support System (PSS). PSS include visualizations, impact analysis, outcomes quantification, indicators and scenario development and evaluation (Lieske \& Hamrlink 2012); the Index of Multiple Deprivation (IMD) is, for example, an indicator based PSS which is often used for area profiling to prioritize regeneration areas and allocate funding.

Previous work has criticized the exclusive use of IMD for area profiling as the aggregate indicators are weighted using, for the most, economic domains (Deas et al. 2003) which do not capture the social dimension of communities. Nevertheless the lack of a specific agenda in PSS has left research in this area unstructured and unsystematic until recently when efforts have put focus on the need of PSS to "redirect means to goals, cooperate with planning practice, pay attention to the context of PSS application and the methodological and conceptual research, move from a case study to real world planning and fit the application of PSS to application specific characteristics” (Geertman, 2009, 2013).

\section{Socio technical design and the principles of compatibility, congruence and minimal criteria} specification

In order to better understand the development of PSS like the IMD in planning, information system design theories such as socio-technical design, user experience and user centred design, appreciate how users and 
their goals are placed at the centre to the design of the information system. In relation to area profiling, Reeve \& Petch (1999) helped to re-think the design of GIS in the context of Local Authorities using a sociotechnical approach. Original socio-technical approaches like Soft System Analysis and ETHICS were used in the 80's and 90's to investigate problems of complex human activity and introduce an ethical basis to system design (Reeve \& Petch 1999). The first principles of socio-technical design are defined in Cherns (1976) and three of these (compatibility, congruence and minimal criteria specification) are found to be particularly relevant to the design and implementation of area profiling tools for bottom up planning. These are:

- Compatibility: The process of design must be compatible with its objectives

- Minimal Critical Specification: no more should be specified than is absolutely essential; but the essential must be specified

- Congruence: systems of social support must be designed to reinforce the desired behaviour.

Lessons drawn from the literature review, interviews and observational studies will be summarised in the context of these three different principles. In this way, concerns from the world of practitioners will be addressed according to existing socio-technical design principles, bringing theory and practice to the same table.

\section{Previous challenges identified in representing communities in GIS}

Previous work dealing with the challenges in representing and profiling communities was identified. In Ham et al (2013), an extensive review of the challenges associated with the representation of neighbourhood is presented. Ham et al. (2013) explain how, in order to represent a neighbourhood, one should deal with the representation of the relationship between the built environment and the subjects of the neighbourhood; moreover, both the consideration of the Temporal variable (people's and places' histories) and the broaden of the neighbourhood's horizon (multiple scale) to include other spatial contexts, are to be considered. In other words, what Ham et al. (2013) suggest, is the abandonment of representations of neighbourhoods as bounded, static and a-temporal phenomena as recalled in other community and neighbourhood related studies. Kwan (2012) presented such methodological challenges as the uncertain geographic context problem (UGCP), which arises because of "the spatial uncertainty in the actual areas that exert relevant contextual influences on each individual under study”, and the modifiable area unit problem (MAUP), in which “analytical results are biased by the zoning scheme” (Kwan, 2012)

\section{Interviews}

Seven semi-structured interviews with senior planners working at five different Local Authorities in the West of Scotland were carried out and used to gather experiences of different practices surrounding area profiling. In two of the five Local Authorities, it appeared that community mapping helped planners to access the negative perspectives of a specific demographic group over what was identified by the planners 
themselves as a positive environmental feature. As one of the planners said "without any doubts, it (community mapping) helped us understand that a space which was perceived as a good space by planners, for the kids (the same space) was perceived as unsafe”. When asked whether they digitize the maps they collected, the same planner replied: “Sometimes we do, sometimes we don't. If we think some information might be used for other departments (e.g. Health) then we might share it with them”. The interviews also found that consultation processes are designed to collect subjective spatial information using a wide range of methods (questionnaire, surveys, public hearing, Charrette etc) which could be carried out by employees from Local Authorities and/or external agencies. However, regardless of who is responsible for the mapping, the interviews revealed that subjective spatial information collected via community mapping during consultation processes or capacity building activities, is usually not stored in GIS of Local Authorities preventing this information from being retrieved in the future. In relation to the possibility of storing the community maps gathered during consultation events, one of the planners stated that: "It could be useful and beneficial and maybe it's what should be done, but we have neither the time nor the resources for this”, suggesting that staffing and resources may represent one of the causes to the loss of subjective spatial information collected throughout consultation processes.

From the interviews it was apparent that, at present, no procedure exists for scanning and digitizing the community maps and that the potential existed to develop this.

\section{Observational studies}

Community mapping is increasingly being deployed to support community planning activities both formal and informal. The research identified instances of community mapping taking place within Glasgow and conducted two observational studies to learn and also evaluate its potential. The first author participated in a training course for community research provided by a Scottish Faith Group working with deprived communities nationwide. In here the researcher was introduced to a 'community research toolkit' in which community mapping was showcased. In addition to this, the researcher was involved in community mapping for a Glasgow based charity where she developed an online mapping tool to facilitate the sharing of information between people with special needs.

These studies clearly showed that community mapping is a popular tool used both in planning as well as in the third sector for capacity building and that a variety of 'mapping methods' were employed: from sketching on blank paper, to drawing on printed maps or using specific web based applications. As part of one of the consultation exercises, Participatory Geographic Information Systems (PGIS) were promoted by one specific group of facilitators funded by Future City Glasgow, a government programme promoting digital innovation (Future City 2016a; Future City 2016b) but analogue mapping methods were perceived to be more widespread and predominant in informal exercises stemming from communities (bottom-up). This was confirmed during the training on community research in which digital mapping tools were not presented as an option for aiding engagement. 


\section{Submap: The design and modelling of a new community mapping procedure} Addressing the limitations of existing techniques

(1)

The literature review, interviews and observational studies identified different problems relating to community mapping. These are summarised in the seven points outlined below and categorised according to the socio-technical design principles on which they have been developed. The attempt to resolve these seven different issues through better design and modelling, have led to the development of a six step procedure for the design and modelling of Submap (Fig.1).

\section{COMPATIBILITY}

1) SPATIAL AND TEMPORAL SCALE: The literature review identified that multiple scales and temporal dimensions should be considered during the design of community maps (Ham et al. 2013) but observational studies demonstrated traditional community mapping procedure fail to do so. In Giupponi and Thomson (2016), it is showed how Submap addressed these issues by including four different scales in four different quadrants on a A2 paper while capturing temporal data like residential history and willingness to move.

2) GENERALISATION: Generalisation is a cartographic design principle which entails the identification of the elements of spatial reality which are to be represented. This process is better illustrated in Giupponi and Thomson (2016) and it essentially justify the selection of the different elements ‘to be mapped during community mapping'. In other words, generalisation processes establish which, out of all the elements of subjective lived space, are to be mapped; for example, it would not be possible to represent all the aspects of the road network because that would be the road network itself. Maps are a simplification of spatial realities and deciding which elements are to be excluded from this representation is an essential aspect of community mapping design which is thought to have been overlooked as the selection of elements to be mapped should be tailored to the purpose of the map and its audience rather than a standard set of elements.

3) REPRESENTATIVENESS: One of the main stages in the process of testing Submap was the sampling of data: how to gather a representative sample of community maps within a specific community? Different sampling methods were tested and direct participation to community events and postal survey resulted to be, respectively, the most and least successful ones. In order to mirror the scientific rigour of traditional neighbourhood profiles, a representative sample is expected to reflect the demography of the community which is to be represented; by gathering information about the individuals participating to community mapping, each community map can be associated to a 
specific anonymous ID which will relate to an attribute table (e.g. age, education, gender, ethnicity, income) and this will effectively illustrate the representativeness of specific community mapping processes.

\section{MINIMAL CRITERIA SPECIFICATION}

4) INTEGRATION: Following socio-technical design principle of minimal criteria specification, it is understood that innovative consultation procedures should not be disruptive rather, they should be integrated to what is seen as common practice; the requirements for the adoption of new technologies should either be minimal or support should be provided to the users of the new system. Following the two observational studies, this meant recognising that, at present, paper mapping may be an easier technique to implement than any other digital format. However, the potential advantages of using digital technologies should not be neglected and, depending on the mapping objectives, the application of digital technologies may well be seen as favourable.

5) ACCESSIBILITY: The interviews demonstrated that community maps are not digitized and securely stored and, as a consequence, information is lost. The digitized community maps and the points, lines and polygons associated to the different individuals who participated to community mapping should then be accessible and retrievable by decision makers in existing GIS.

\section{CONGRUENCE}

6) RELATEDNESS: According to the socio-technical design principle of congruence (Cherns, 1976), a new information system should be designed “in a way to support the desired behaviour”. It is then crucial to clarify which is the desired behaviour associated with 'inclusive area profiling'. Findings from the interviews revealed that area profiles are created by GIS technicians and capable planning practitioners using different datasets often stored in in a Spatial Database Engine (SDE). However, from the interviews it was understood that no datasets with subjective representations of neighbourhoods are stored in such folders. Inclusive area profiling would therefore relate subjective mappings to the existing data sets used for area profiling. The data extracted from community mapping (as well as other multimedia collected during consultation processes, representative of spatial representation of lived spaces) can be related to the same geographic unit used for developing area profiles in Local Authorities: the datazones. By doing so, both objective (quantitative) and subjective (qualitative) spatial information are integrated in a single database accessible by multiple users.

7) VISUALISATION: The community maps should be visualised in GIS to promote sense making during activities. Visualisation is a pivotal aspect of mapping as it enhances sense making and improve communication (MacEachren \& Brewer, 2004). One of the planners interviewed iterated that "all we do is visual, everything is about maps"; this is why it is essential to think about the visualisation component and how this could aid sense making. 
After having discussed the nature of the seven problems of contemporary community mapping practices as identified from primary and secondary data, the Submap GIS relational geodatabase (Fig. 2) was conceptualy and physically modelled to store community mapping data extracted from community mapping activity using Submap and addressed issues of accessibility (5) and relatedness (6). A geodatabse is a collection of spatial and non-spatial datasets of various types (vector, raster, table, BLOB) in which the data is held in a common file system folder. The ArcGIS relational database as illustrated in Fig. 2 was then developed to ensure that community mapping activities carried out during consultation processes could be stored and retrieved by different users and the relationships with other spatial datasets could be interrogated using spatial queries and elements selected by attributes (e.g. 'select dangerous places by gender’). The paper map Submap (Giupponi and Thomson 2016) was used to carry out the community mapping from nineteen different individuals living in the same community. Community maps were collected using different sampling methods in the Gorbals, Glasgow which demonstrated the challenges of gathering a representative sample and investigate representativeness (3). Details about the design of Submap and how it included different spatial and temporal scales (1) through generalisation and composition, are discussed in Giupponi and Thomson (2016) where the design of an A2 sized paper map including four different scales (local, city, national and world wide) and attribute data (residential history, willingness to move, attachment, demographic data etc) was presented.

\section{Summary of findings}

The results from this work into the potential of GIS in facilitating better area profiling based on community mapping did not simply lead to the development of a procedure or a map but sketched out a methodological approach made of some theoretical assumptions, procedures, tools and limitations for community mapping.

Firstly, there is the paper map Submap, used to systematically collect subjective spatial data at different spatial scales and relate them to the respondent attributes through careful cartographic design; Secondly, there is Submap mapping activity in which social research methods are required to collect a representative sample of the community; Thirdly, we have developed Submap geodatabase, used to store community based spatial data in existing GIS enterprises and relate it to existing datasets for the same output area. Fourthly, Submap visualisation techniques were recognised to be key to communicate community based profiling. Finally, there is Submap procedure, developed as a result of this process for individuals willing to implement Submap (Fig. 1).

Limitations to the implementation of the procedure are anticipated and relate to the skills required for the digitization and storage of community maps in GIS including the georeferencing of scanned maps, editing and general data input. Professionals involved in consultation processes using paper based community mapping as a tool to gather community perspectives would be required to follow a systematic procedure 
1 starting with the selection of the different scales and the different elements to map and ending (whether the

2 same person or someone else will depend) with the digitization and storage of such information in GIS in

3 order to make it retrievable by other GIS users using spatial queries. Problems around sample

$4 \quad$ representativeness (3) and visualisation techniques (7) will be discussed in future publications by presenting

5 the challenges faced to gather a representative sample of the community in the Gorbals and the different

6 visualisation techniques that could effectively enhance sense making and communication (MacEachren \&

7 Brewer, 2004) as introduced below in Figure 3 and Figure 4.

8

9 
Fig. 4 Visualisation of Submap polylines (daily routes) without a baseline map

\section{Lessons for the future and conclusions}

In discussing radical planning, Sandercock (1998) suggested that "an epistemology of social learning and of multiplicity will require the development of new ways of knowing and acting”. This piece of research on community mapping offered a new way of doing community mapping which could have different effects on both the world of planners and the world of practitioners. On one side, communities would be required to be systematic in generating their ideas so that community based information could fit existing spatial information structures. On the other side, planners and the other stakeholders involved in consultation as well as area profiling for urban regeneration, would have to welcome subjective maps to existing information structures. This transformational approach recalls radical planning principles positioning itself with Friedmann's idea of a productive tension: by providing communities with an exact procedure that would allow their own mappings be included in the common file folders accessed by planners for community profiling, the state and its government technologies are not seen as an adversary to the process of radical planning and planners are able to maintain a critical distance without becoming absorbed in the everyday struggle of radical practice (Sandercock, 1998).

Secondly, this research revealed the methodological weakness of contemporary consultation tools like community mapping and critically ask whether transforming a mix of incoherent and methodologically flawed techniques for consulting communities into more systematic procedures could really aid bottom up planning or whether this will just result into another kind of bureaucratic burden. Would it be unreasonable 
1 to ask the actors involved in organising four days' Charrettes to gather community perspectives using a

2 representative sample and store it in a format which can be digitized and retrieved in GIS? If yes, why are

3 we, in the era of digital transformation (Cabinet Office, 2017), treating spatial information created by

4 different groups differently? Why community based spatial is treated different than the spatial data generated

5 for a drainage impact assessment or a transport assessment?

6 To summarise, investigation into the very marginal aspect of community mapping in consultation processes

7 revealed important questions about the practical implications of moving beyond the qualitative and

8 quantitative chasm of geography (DeLyser \&Sui, 2013) in the context of community based planning; the

9 main research contribution is not the innovative community mapping activity itself but it is the attempt to

10 ultimately include the data produced during consultation activities (from community maps to Place Standard

11 diagrams, multimedia etc.) in the same GIS database used for traditional area profiling by decision makers.

12 Whether reducing distances between datasets could really decrease distances between the subjective and the 13 objective worlds, the informal and the formal and the expertise and the experience, remains a question to 14 answer which will not only require only more testing and learning (Brömmelstroet, 2016) but it may require new philosophies in which "the elements of planning, these non-human things, can be used to theorize planning” (Beaurigard, 2016). 


\section{REFERENCES}

Beaurigard R.A. (2016) Planning Matter: Acting with Things University of Chicago Press

Brömmelstroet, M. (2016) Towards a pragmatic research agenda for the PSS domain. Transport. Res. Part A, http://dx.doi.org/10.1016/j.tra.2016.05.011

Brown G. \& Kytta M. (2014) Key issues and research priorities for public participation GIS (PPGIS): A synthesis based on empirical research Applied Geography 46, 122-136

Brudney J.L., Russell A. \& Fischer R.L. (2017) Using data to build community: exploring one model of geographically specific data use in the non-profit sector Community Development Journal Vol. 52 pp.354371 DOI: $10.1093 / \mathrm{cdj} / \mathrm{bsw008}$

Cabinet Office, 2017 Government Transformation Strategy 2017 to 2022 Available at https://www.gov.uk/government/publications/government-transformation-strategy-2017-to2020/government-transformation-strategy [6th July 2017]

Cherns A. (1976) The principles of socio-technical Design Human Relations 29 (8) 783-792

Crampton, J. (2006) Mapping: a critical introduction to GIS and cartography Oxford: Blackwell , in pres

Deas, I., Robson, B., Wong, C., \& Bradford, M. (2003) Measuring Neighbourhood Deprivation: A critique of the Index of Multiple Deprivation. Environment and Planning C 21, 883-903.

DeLyser D \& Sui D (2013) Crossing the qualitative-quantitative chasm III: enduring methods, open geography, participatory research, and the fourth paradigm. Progress in Human Geography. Epub ahead of print 19 March 2013. DOI: 10.1177/0309132513479291

Fincher R., Pardy M. \& Shaw K. (2016) Place-making or place-masking? The everyday political economy of “making place”, Planning Theory \& Practice, 17:4, 516-536, DOI: 10.1080/14649357.2016.1217344

Forester J. (2013) "On the theory and practice of critical pragmatism: Deliberative practice and creative negotiations” Preprint for Planning Theory doi: 10.1177/1473095212448750

Friedmann J. (2010) Place and Place-Making in Cities: A Global Perspective Planning Theory \& Practice, Vol. 11, No. 2, 149-165

Future City (2016a) MyGlasgow Prototyping a New and Improved Citizen app Online Available from: http://futurecity.glasgow.gov.uk/my-glasgow last access 28th June 2016

Future City (2016b) What is Open Glasgow? http://futurecity.glasgow.gov.uk/my-glasgow last access 28th June 2016

Geertman S. (2013) Planning support: from systems to science Proceedings of the Institution of Civil Engineers Urban Design and Planning 166 (DP1) 50-59

Geertman S \& Stillwell J. (2009) Planning Support Systems: Best Practice and New Methods Advances in Spatial Sciences Springer, Berlin, Germany.

Giupponi N. \& Thomson C. (2016) 'Submap: a conceptual and physical model of a spatial database for collaborative planning', $51^{\text {st }}$ International Congress Report E-Book, Cities Save the World. Let's Reinvent Planning. Edited by Judith Ryser ISBN: 978-94-90354-45-9 Available from https://isocarp.org/activities/isocarp-annual-world-congress-2/51st-isocarp-congress-netherlands- 
belgium-germany-19-23-october-2015/52nd-international-congress-report-e-book/ Copyright: (C ISOCARP 2016n[11th November 2017]

3 Glasgow City Council (2017) Glasgow City Development Plan Available at

4 https://www.glasgow.gov.uk/CHttpHandler.ashx?id=35882\&p=0 [6th July 2017]

Habraken N. J. (1972) Supports: An Alternative to Mass Housing London: Architectural Press

Hall P. (1996) Cities of Tomorrow: updated edition Blackwell Publishers

Ham MV, Manley D. , Bailey N., Simpson L., Maclennan D. (2013) Neighbourhood effects research at a crossroads: ten challenges for future research OTB working paper 2012-2013 Research Institute for the Built Environment Delft University of Technology

Harris, RJ, Sleight, P \& Webber, R (2005) Geodemographics, GIS and Neighbourhood Targeting Wiley

Healey P (1998) Building institutional capacity through collaborative approaches to urban planning Environment and Planning A 30 1531-1546

Jenkins P. \& Forsyth L. (2010) Architecture, Participation and Society, Abingdon: Routledge. Available online at https://core.ac.uk/download/pdf/1662349.pdf [6th July 2017]

Khaldun, Ibn. (1969) The Muqaddimah, Edited by: Rosenthal, F. 59-61. Princeton: Princeton University Press.

Kheir A. (1999) Visualization Tools and Public Participation: From Crayons to Computers Critical Planning

Kolb, D.A. (1984) Experiential Learning: Experience as the Source of Learning and Development Prentice Hall, New Jersey.

Kwan MP (2012) The uncertain geographic context problem Annals of the Association of American

Geographers 102(5):958-968

Lefbvre, D. (1991) The production of space Publisher: Oxford, OX, UK ; Cambridge, Mass., USA :

Blackwell, 1991

Lieske S. Hamrlink J. (2012) Planning support systems applications in site planning Proceedings of the Institution of Civil Engineering Urban Design and Planning 166 (DP1) 34-42

Local Government Association (2017) People, culture, place: The role of culture in placemaking Available at https://www.local.gov.uk/sites/default/files/documents/12.3\%20\%20culture\%20and\%20place_v4_1_1.pdf [6 ${ }^{\text {th }}$ July 2017]

Longley P.A. (2012) Geodemographics and the practices of geographic information science, International Journal of Geographical Information Science, 26:12, 2227-2237, DOI: 10.1080/13658816.2012.719623

MacEachren A.M. \& Brewer I (2004) Developing a conceptual framework for visually-enabled geocollaboration , International Journal of Geographical Information Science, 18:1, 1-34, DOI: 10.1080/13658810310001596094

Madanipour A. (2017) Temporary use of space: Urban processes between flexibility, opportunity and precarity Urban Studies 1-17 
Marris P. (1998) Planning and Civil Society in Twenty-first Century: an introduction in Cities for Citizens edited by Mike Douglass and John Friedmann John Wiley \& Sons

Mathie A. \& Cunningham G. (2003) From clients to citizens: Asset-based Community Development as a strategy for community-driven development, Development in Practice, 13:5, 474-486, DOI $10.1080 / 0961452032000125857$

Monno V. \& Khakee A (2012) Tokenism or Political Activism? Some Reflections on Participatory Planning, International Planning Studies, 17:1, 85-101, DOI: 10.1080/13563475.2011.638181

Nedovic-Budic Z (2000). Geographic information science implications for urban and regional planning. URISA Journal 12(2): 81-93.

Pickles, J. (1995) Ground truth: the social implications of geographic information systems. New York: Guilford .

Pollock V.L. \& Paddison R. (2014) On place-making, participation and public art: the Gorbals, Glasgow, Journal of Urbanism: International Research on Placemaking and Urban Sustainability, 7:1, 85-105, DOI: 10.1080/17549175.2013.875057

Reeve D.E. \& Petch J. (1999) GIS, Organisations and People: A Socio-technical Approach Taylor \& Francis

Rydin Y. (2007) Indicators as a governmental technology? The lessons of community-based sustainability indicator projects Environment and Planning D: Society and Space 25(4) 610 - 624

Rydin Y. (2013) The future of planning: Beyond growth dependence Policy Press

Sandercock (1998) L. The Death of Modernist Planning: Radical Practice for a Postmodern Age in Cities for Citizens edited by Mike Douglass and John Friedmann John Wiley \& Sons

Schaller S. \& Guinand S. (2017): Pop-up landscapes: a new trigger to push up land value?, Urban Geography, DOI: 10.1080/02723638.2016.1276719

Scotland Census (2017) Area Profile http://www.scotlandscensus.gov.uk [6 ${ }^{\text {th }}$ July 2017]

Scottish Executive (2007) Planning Advisory Note 81 Community Engagement - Planning with People http://www.orkneywind.co.uk/advice/SE\%20pan81\%20community\%20engagement.pdf $\left[20^{\text {th }}\right.$ November 2017]

Scottish Government (2014) Scottish Index of Multiple

Deprivation http://www.scotland.gov.uk/Topics/Statistics/SIMD [12th August 2014]

Scottish Government (2015) Thriving Places: An Intensive Neighbourhood Approach Single Outcome Agreement Review 29-33

Scottish Government (2016a) A Draft Report Public Participation in Decision Making, The Scottish Government and The Democratic Society

Scottish Government (2016b) SSCI Charrette Mainstreaming Programme Online http://www.gov.scot/Topics/Built-Environment/AandP/Projects/SSCI/Mainstreaming last access 28th June 2016 
1 Scottish Government (2017) Place standard: How Good is Our Place https://placestandard.scot [6 $6^{\text {th }}$ July 2 2017]

3 Scottish Parliament (2014) Community Empowerment (Scotland) Bill, introduced in the Scottish Parliament 4 on 11 June 2014

5 Spatial Agency (2017) Community Technical Aid Centres University of Sheffield

6 http://www.spatialagency.net/database/community.technical.aid.centres [6th July 2017]

7 The Guardian (2013) The pop-up designs changing the city landscape

8 https://www.theguardian.com/artanddesign/2013/aug/03/pop-up-designs-architecture-london

9 Towers, G. 1995 Building Democracy: Community Architecture in the Inner Cities London: University Col10 lege London Press

11 White, SC 1996. "Depoliticising Development: The Uses and Abuses of Participation.” Development in 12 Practice. 6 (1): 28-32. 
Figure 1: Submap Procedure

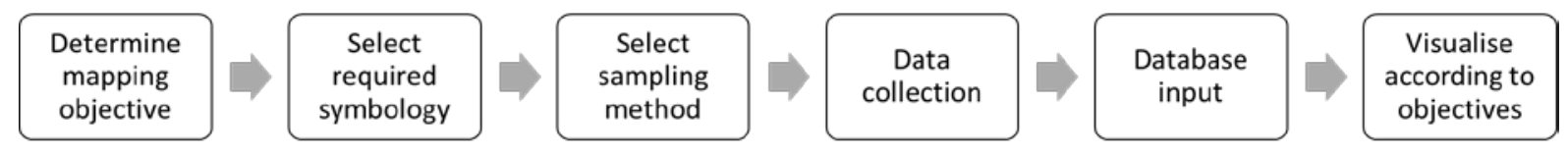

Figure 2: Submap ArcGIS relational geodatabase: conceptual modelling

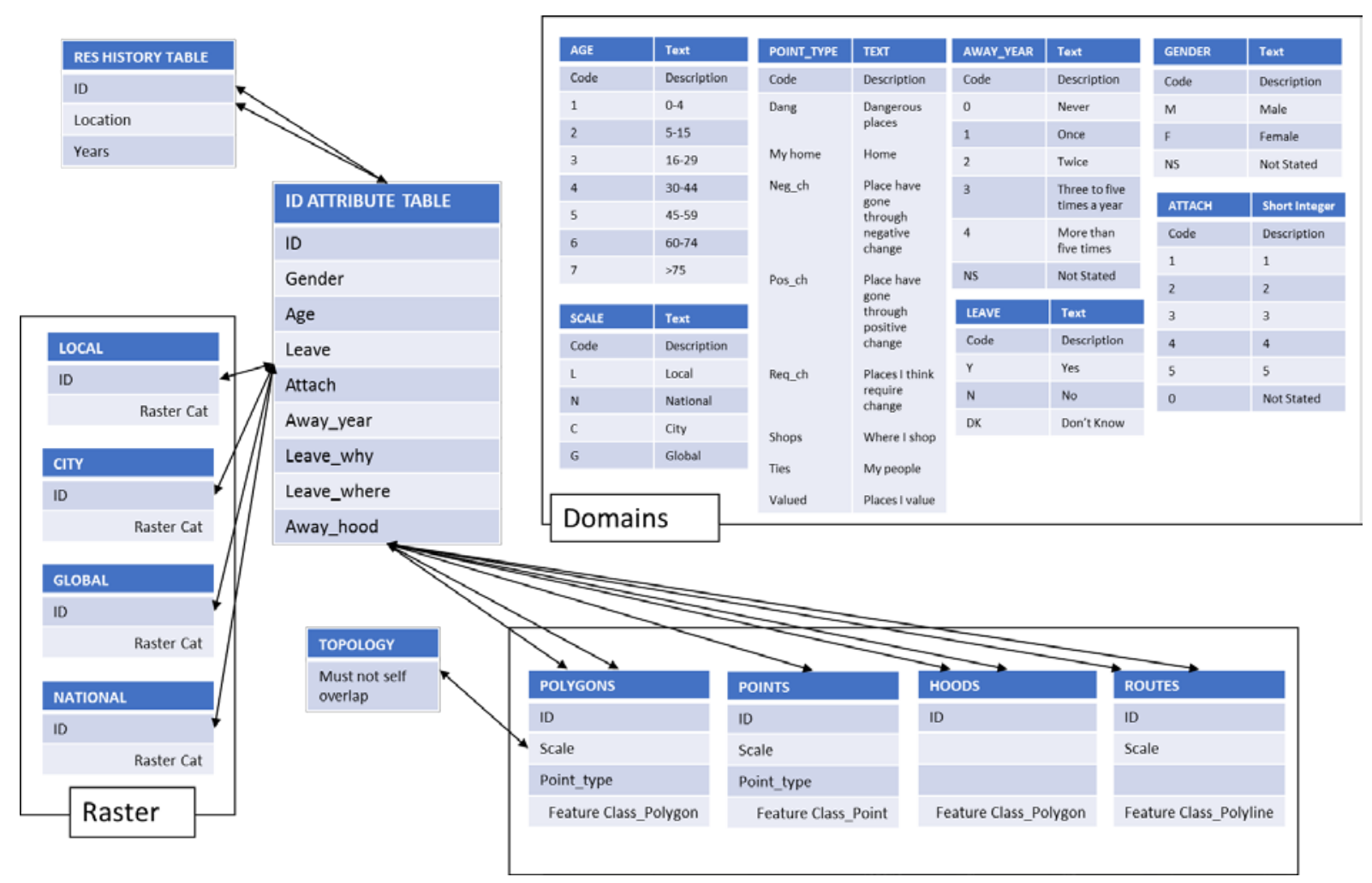


Figure 3: Visualisation of Submap 'My Shops'

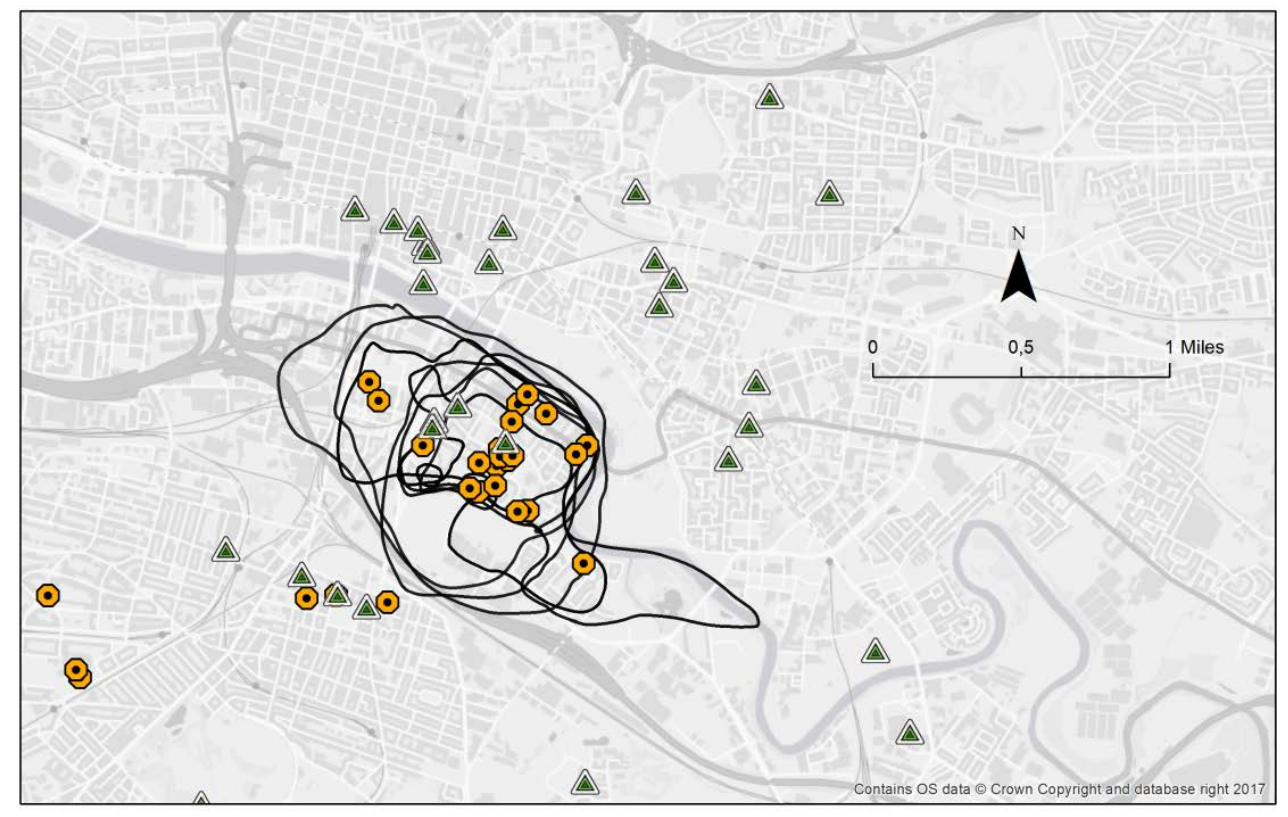

Figure 4: Visualisation of Submap polylines (daily routes) without a baseline map

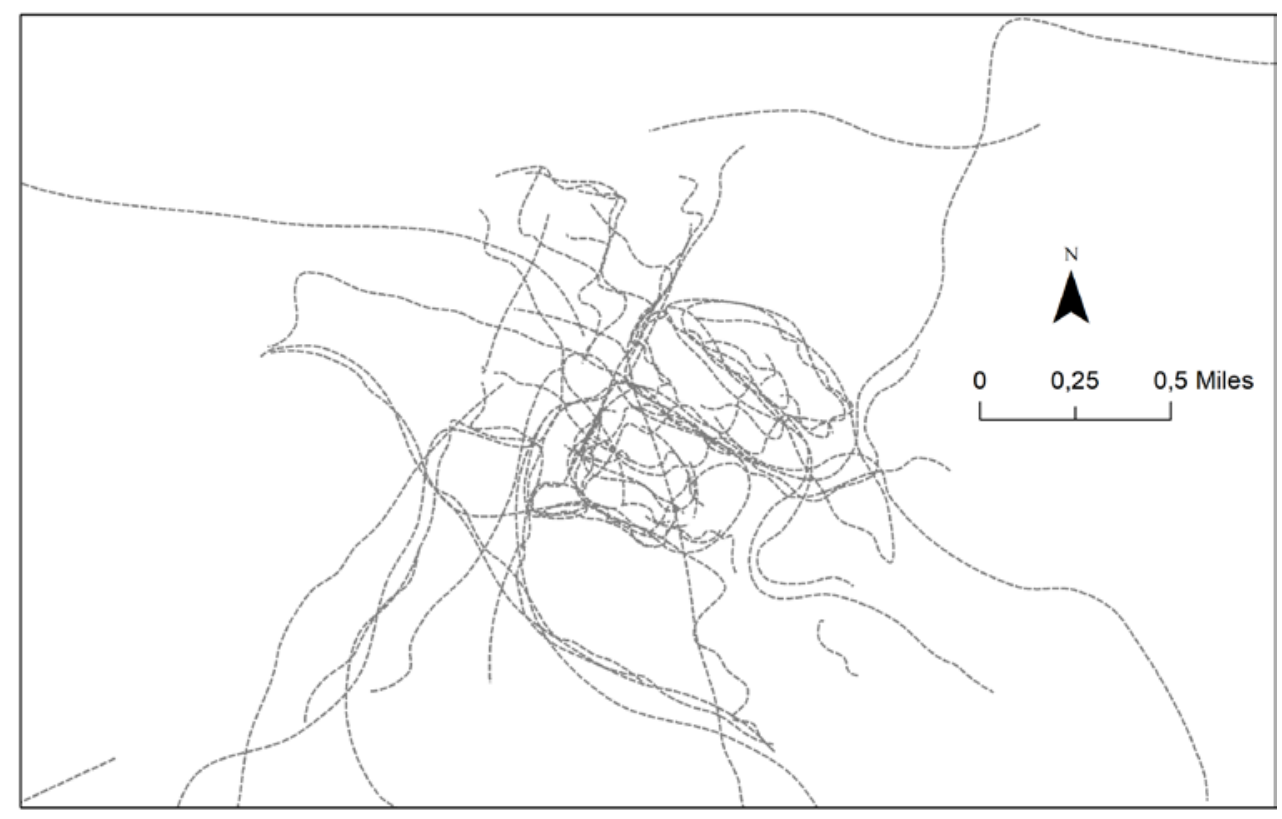

